past year, during the whole of which period patient's red blood count has been at a satisfactorily high level.

5 . Optic atrophy does not exist, though possibly one disc is a little paler than the other.

6. Pupils continue to react to light.

7. Central relatize scotomata exist, suggestive of retro-bulbar neuritis, and the visual fields are full.

I suggest that the eye condition might be accounted for by a de-myelination of the optic nerves comparable to the de-myelination of the postero-lateral columns found in sub-acute combined degeneration. The comparatively little interference with the axis cylinders would account for the non-development of optic atrophy.

I wish to thank Dr. C. C. Beatty, under whose care this patient is, for the notes on the progress of the anaemia.

\title{
A RETENTION CYST OF UNUSUAL SIZE, PROBABLY OF KRAUSE'S GLAND, SIMULATING ANGIOMA OF THE ORBIT
}

\author{
BY \\ D. V. GIRI \\ EASTBOURNE
}

DOREEN M. was first seen by me in January, 1928, at the Royal Eye Hospital, Eastbourne, at the age of 6 years, because of eyestrain, and a low hypermetropic correction was ordered. At the time nothing abnormal about her eyes or adnexa was noted. Again in February, 1929, and January, 1930, the eyes were refracted and nothing abnormal was found. In March; 1931, she came complaining of a lump on the upper lid of the R.E. at the inner end of the brow which " came and went," being sometimes very prominent and sometimes hardly noticeable. Sometimes she felt something "going over" and then it pained. On making the child bend her head forward a slight bulge was noticed. The consistency of the lump was probably soft but could not be definitely made out as it receded so easily on palpation.

When she was seen again in April, 1932, a cystic tumour-.. smooth, mobile, and non-adherent to the skin, could be distinctly felt at the upper inner angle of the orbit. By November, 1932, it was obvious to the naked eye and could easily be made prominent by bending the head forward. The patient gave a history of some bleeding from under the right upper lid without any apparent cause one day in the class-room. Eversion of the upper lid did not expose the tumour. 
The case was referred to Mr. D. E. O'Connor Cuffey at the Eastbourne Ear, Nose, and Throat Hospital and he found that the tumour had no connection with any of the sinuses.

Dr. G. P. Norman, Head of the X-ray department of the Princess Alice Memorial Hospital, found no bony changes radiographically.

The girl and her parents wished to have the tumour removed.

On May 1, 1934, under local novocaine-adrenalin infiltration कs anaesthesia, an incision along the upper orbital margin about $1 \overrightarrow{.}$ inch long corresponding to the tumour was made, and by careful $\overrightarrow{\vec{\omega}}$ retraction and separation of the tissues with a blunt dissector and $\stackrel{\rho}{\omega}$ retractors and occasional snips with the scissors, a smooth, pale $\frac{\sigma}{\circ}$ white, translucent oval cyst, about $3 \mathrm{~cm}$. long and $1.7 \mathrm{~cm}$. त् broad, was removed undamaged. The cyst was hardened in Zenker's fluid and sent to Mr. E. Wolff at the Royal Westminster $\vec{\sigma}$ Ophthalmic Hospital for histological examination, whose report $\stackrel{\sim}{\longrightarrow}$ runs as follows :-

"This is a cyst lined for the most part by two layers of cells, a deeper flattened and a more superficial cubical. In parts there $z$ are several layers of cells resembling altered conjunctiva. There $\Phi$ is a well-marked fibrous tissue wall, and here and there nodules of lymphocytes. The cyst is most probably a retention cys arising from the conjunctiva or gland of Krause. It is not as ordinary dermoid."

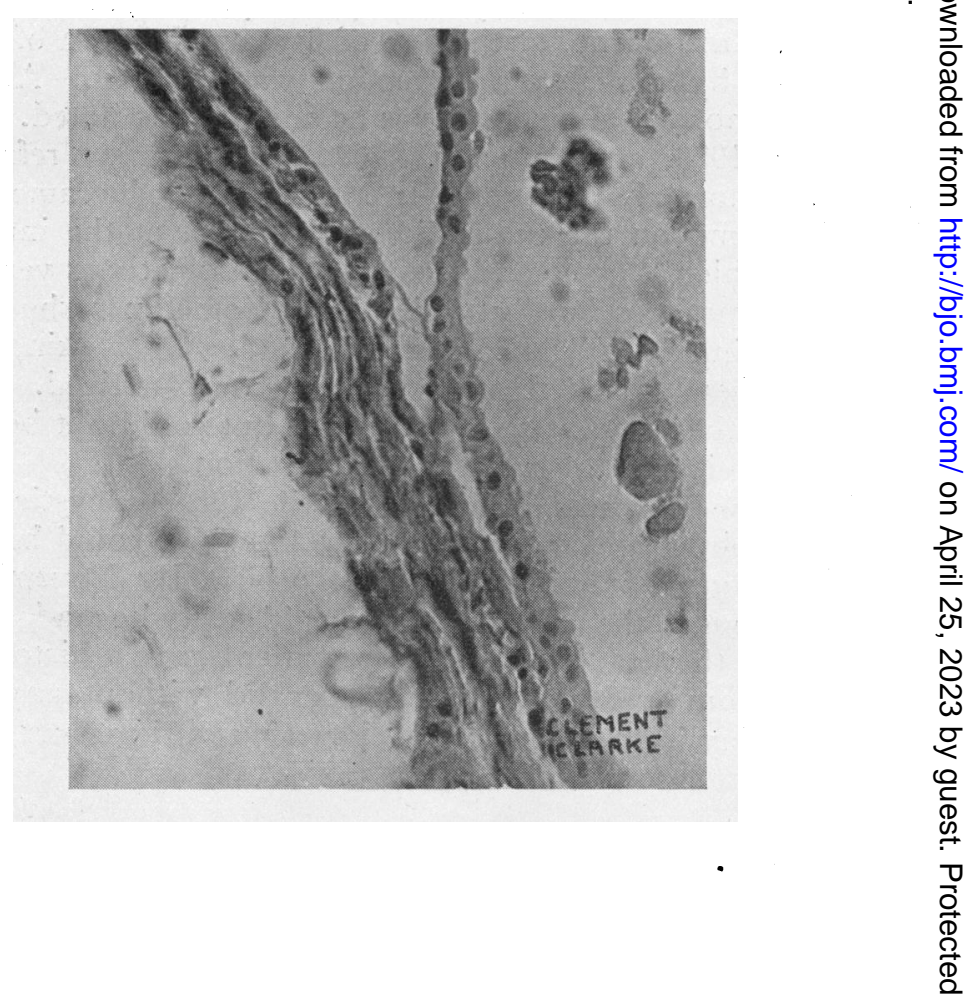




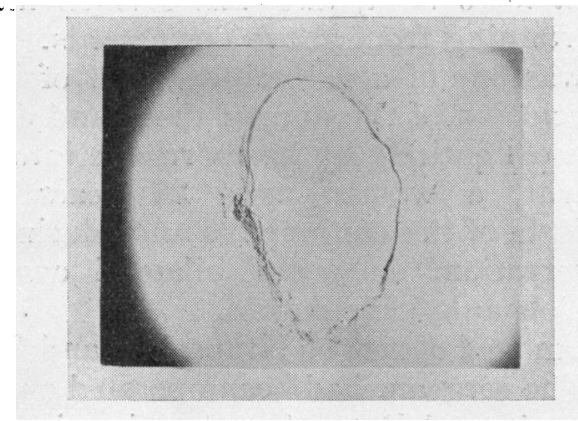

Section of hardened cyst. Actual size.

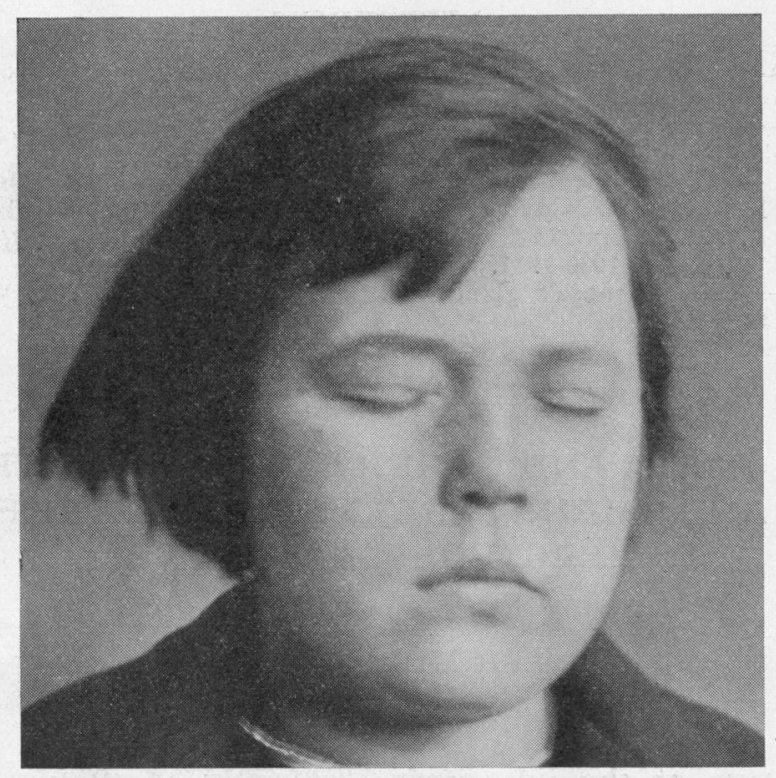

This is the first instance of the kind that has come under my notice. Considering the small number of cases recorded it is probably a rare occurrence. In the literature I have been able to gather only 5 cases of probable retention cyst of Krause's glands. Each of them differs from my case. None of them disappeared into the orbit or increased in size so strikingly on bending the head forward as in my case. Except perhaps the large conjunctival cyst described by Harrison Butler in "The Ophthalmoscope" in 1907, all arose from cicatricial conjunctiva; in my case there was no such complication. Contino's patient was a woman of 22 years of age who had suffered from trachoma from childhood; the cyst 
measured $22 \mathrm{~mm}$. $\times 10 \mathrm{~mm}$., and was divided into 3 loculi by cicatricial bands running from above downwards.

Caocci's case was one of a voluming cyst of Krause's gland resulting from occlusion of the duct of the gland due to trachoma and distended almost entirely by haemorrhage into it.

Michail's patient, a woman aged 26 years, suffered from bilateral tuberculosis of the conjunctiva and, during a course of $3 \stackrel{\mathbb{}}{2}$ years under observation, developed bilateral cysts of Krause's क glands and complete ankyloblepharon.

Leslie Paton removed a cyst of Krause's gland from a sergeant aged 32 years. The sergeant had been operated on for a chalazion $\vec{\omega}$ some time previously and Paton found a cicatrix in the conjunc- $\frac{\partial}{0}$. tiva covering the cyst.

\section{REFERENCES}

Contino, A.-Grossa Cisti della ghiandola di Krause con particolare reperto istologico. Clin. Ocul., Vol. VII, pp. 2509-2517, 1906.

Caocci, G.-Rass. Ital. d'Ottal., Vol. I, 1932, abstracted in Amer. Jl. of Ophthal., 을 Vol. XVI, p. 900, 1933.

Michai1, D.-Ankylosing tubercu osis of the cor junctiva with large bilateral cysts $Z$ of Krause's glards and cystic degeneration of Meibomian glands. Cluj. Med., Vol. X, pp. 273-276. Abstracted Zentralbl.f.d. ges.. Ophthal., Vol. (D XXIV, p. 230, 1930-1931.

Paton, L.-Cyst of Krause's gland. Trans. Ophthal. Soc. U.K., Vol. XXXIX p. $129,1919$.

PAPILLOMATA AND OTHER TUMOURS OF THE LIDS AND THEIR TREATMENT WITH THE ELECTROLYSIS NEEDLE

BY

Joseph Minton, F.R.C.S.

LONDON

Papillomata of the lids occur frequently in middle-aged and elderly people of both sexes. They are more common on the lower lids. The pedunculated and sessile varieties occurring on the skin of the lids have been well described in most text-books, 공 but very little has been said about the superficial wart-like pro- o cesses situated upon the intermarginal area of the lids.

This variety of papillomata is seen in various forms : (1) A raised reddish tumour stretching from the ciliary margin to the internal margin of the lid; (2) marginal papillomata; (3) a flat papilloma growing from the skin of the lid, involving the ciliary margin and $N$ c portion of the intermarginal area. Most of these papillomata are hlat and of the sessile variety. 